\title{
PET/CT incidental detection of second tumor in patients investigated for pancreatic neoplasms
}

\author{
Lucia Moletta ${ }^{1}$, Sergio Bissoli ${ }^{2}$, Alberto Fantin ${ }^{3}$, Nicola Passuello ${ }^{1}$, Michele Valmasoni ${ }^{1}$ and Cosimo Sperti ${ }^{1 *}$ (D)
}

\begin{abstract}
Background: Positron Emission Tomography/computed tomography (PET/CT) is an imaging technique which has a role in the detection and staging malignancies (both in first diagnosis and follow-up). The finding of an unexpected region of FDG (Fluorodeoxyglucose) uptake can occur when performing whole-body FDG-PET, raising the possibility of a second primary tumor. The aim of this study was to evaluate our experience of second primary cancer incidentally discovered during PET/CT examination performed for pancreatic diseases, during the initial work-up or follow-up after surgical resection.
\end{abstract}

Methods: In this study, a retrospective evaluation of a prospectively collected data base was performed. Three hundred ninety- nine patients with pancreatic pathology were evaluated by whole body PET/CT imaging from January 2004 to December 2014. Among them, 348 patients were scanned before surgical resection and 51 during the course of their follow-up (pancreatic cancer). Median follow-up time was 29 months (range 14-124).

Results: Fifty-six patients (14\%) had incidental uptake of FDG in their organs: 31 patients had focal uptake and 25 showed diffuse with or without focal uptake. All patients with focal uptake were investigated, and invasive malignancy was diagnosed in 22 patients: 14 colon, 4 lung, 1 larynx, 1 urothelial, 1 breast cancer, and 1 colon metastasis from pancreatic cancer. Twenty patients underwent resection, and 6 endoscopic removal of colonic polyps. Three patients were not operated for advanced disease, and two patients did not show any pathology (PET/CT false positive). Of the 10 patients investigated for diffuse uptake, no malignancy was found; none of these patients developed a second cancer during the follow-up.

Conclusions: As in other malignancies, unexpected FDG uptake can occur in patients having PET/CT investigation for pancreatic diseases. Focal uptake is likely to be a malignancy and deserves further investigations, although the stage and the poor prognosis of primary pancreatic cancer should be kept in mind. Some selected patients may benefit from the aggressive treatment of incidental lesions and show survival benefit.

Keywords: Incidentaloma, Pancreas, Pancreatic neoplasms, Positron emission tomography, Surveillance

\section{Background}

Positron Emission Tomography/computed tomography (PET/CT) is an imaging technique which has a role in the detection of malignancies and in cancer staging (both in first diagnosis and follow-up) [1, 2], including pancreatic neoplasms [3]. The finding of an unexpected region of FDG uptake can occur when performing whole-

\footnotetext{
* Correspondence: csperti@libero.it

'Department of Surgery, Oncology and Gastroenterology, 3rd Surgical Clinic, University of Padua, Padua, Italy

Full list of author information is available at the end of the article
}

body FDG-PET; this raises the possibility of a second primary tumor [4]. In the past decade, incidental cancer has been detected by PET/CT in asymptomatic patients [5], patients with head neck cancer [6], oesophagogastric malignancies [7], lymphoma [8], and lung cancer [9]. Informations regarding $\mathrm{PET} / \mathrm{CT}$ incidental cancer in patients with pancreatic neoplasms are still lacking. Aim of this study was to assess the frequency and significance of incidental findings reported by PET/CT scans in patients investigated for pancreatic lesions, both benign and malignant.

(C) The Author(s). 2018 Open Access This article is distributed under the terms of the Creative Commons Attribution 4.0 International License (http://creativecommons.org/licenses/by/4.0/), which permits unrestricted use, distribution, and 


\section{Methods}

Patients who underwent PET/CT examination for staging or follow-up after resection of pancreatic tumors observed in our Department from January 2004 to December 2014, were identified from a prospectively collected database. The scans were reviewed and any incidental findings recorded. One person (SB) assessed all PET/CT reports. An incidental finding was defined as a significant area of FDG uptake in a site unlikely to be related to the pancreatic neoplasm. FDG uptake was described according to focal or diffuse pattern assessed by the nuclear medicine physician. Clinical, radiographic, endoscopic, surgical and pathological records, and follow-up imaging were used as evaluation of incidental PET findings. A validation of the diagnosis was based on the pathologic findings of a resected specimen, biopsy examination, or follow-up. When an extrapancreatic or focal uptake of 18-FDG was detected, an additional diagnostic work-up was performed. All suspected lesions underwent histological confirmation. 18F-FDG PET scans were performed using standard clinical protocols by a hybrid system (Biograph Sensation 16, Siemens, provided with a multislice CT and LSO crystals). A minimum fasting time of $6 \mathrm{~h}$ was prescribed and blood glucose levels less than $120 \mathrm{mg} / \mathrm{dl}$ before intravenous injection of a weight-based amount of 18-FDG (37 MBq/10 kg) were obtained. The CT scans were performed without oral and/or intravenous contrast medium. Cross-sections for attenuation correction of the emission images (when the PET tomograph without CT was used) were obtained with two transmission scans of the abdomen by $68 \mathrm{Ge} / 68 \mathrm{Ga}$ rod sources before the administration of 18-FDG. When using the hybrid system, CT scan was done with a kCp of 120 and weight-based amperage of 120 mAs. PET scan (for both tomographs) began $90 \mathrm{~min}$ after the tracer's injection acquiring 2 beds (16 cm each) to cover upper abdomen area. Coronal, sagittal and transaxial sections were obtained for visual analysis. In the suspected neoplastic areas, a quantitative analysis was performed through the calculation of the maximum standardized uptake value (SUVmax, SUV = tissue tracer concentration/injected dose/body weight) which was analyzed by placing a circular region of interest (on transaxial sections) over the area of maximal focal 18-FDG uptake. We established a SUVmax cut-off of 2.5 or greater according to our previous experience. The PET scan was interpreted by a single observer (S.B.) without knowledge of the CT scan results.

\section{Results}

A total of 399 patients underwent PET/CT imaging during the study period: 348 in the initial work-up for pancreatic neoplasm, and 51 in the course of follow-up after resection for pancreatic cancer. Incidental FDG uptake was identified in 56 patients (14\%): in these patients, pancreatic neoplasms included ductal adenocarcinoma $(n=32)$, intraductal papillary mucinous neoplasms (IPMNs, $n=21$ ), cystic neoplasms (two mucinous tumors and 1 solid-pseudopapillary tumor). Forty-five patients underwent PET/CT at initial stage and 11 during the course of their follow-up after resection of pancreatic cancer. Thirty-one patients (55\%) had focal uptake, while 25 (45\%) showed diffuse with or without focal uptake. Focal uptake was observed in the colon $(n=21)$, lung $(n=4)$, rectum $(n=2)$, larynx $(n=1)$, urether $(n=1)$, breast $(n=1)$, duodenum $(n=1)$ (Table 1$)$. Diffuse with or without focal uptake was observed in the colon $(n=20)$, rectum $(n=2)$, thyroid $(n=2)$, oesophagus

Table 1 Site of incidental findings, results of investigation, treatment and outcome of patients with PET/CT extra-pancreatic focal uptake of the radiotracer

\begin{tabular}{|c|c|c|c|c|c|c|}
\hline \multirow[t]{2}{*}{ Site } & \multirow{2}{*}{$\begin{array}{l}\text { Total Number } \\
\text { of Patients }\end{array}$} & \multirow[t]{2}{*}{ Pathology } & \multirow{2}{*}{$\begin{array}{l}\text { Number } \\
\text { of patients }\end{array}$} & \multirow[t]{2}{*}{ Treatment } & \multicolumn{2}{|c|}{ Outcome } \\
\hline & & & & & $\overline{\mathrm{N}^{0}}$ & $\mathrm{~A} / \mathrm{D}(\mathrm{mo})$ \\
\hline \multirow[t]{4}{*}{ Colon } & \multirow[t]{4}{*}{19} & \multirow[t]{2}{*}{ Adenocarcinoma } & \multirow[t]{2}{*}{14} & \multirow[t]{2}{*}{ Colectomy } & 13 & $\mathrm{D}$ \\
\hline & & & & & 1 & $A(61)$ \\
\hline & & Pancreatic cancer metastasis & 1 & $C T$ & 1 & $\mathrm{D}(8)$ \\
\hline & & HGD & 4 & ER & 4 & $\mathrm{D}$ \\
\hline \multirow[t]{2}{*}{ Rectum } & \multirow[t]{2}{*}{2} & \multirow[t]{2}{*}{ HGD } & \multirow[t]{2}{*}{2} & \multirow[t]{2}{*}{ ER } & 1 & $\mathrm{D}$ \\
\hline & & & & & 1 & A (74) \\
\hline \multirow[t]{2}{*}{ Lung } & \multirow[t]{2}{*}{4} & \multirow[t]{2}{*}{ Adenocarcinoma } & 3 & Lobectomy & 3 & $\mathrm{D}$ \\
\hline & & & 1 & $\mathrm{CT}$ & 1 & $\mathrm{D}(13)$ \\
\hline Breast & 1 & Ductal Carcinoma & 1 & $\mathrm{CT}$ & 1 & $\mathrm{D}(7)$ \\
\hline Ureter & 1 & Urothelial Cancer & 1 & Nephrectomy & 1 & $D(21)$ \\
\hline Duodenum & 1 & $\mathrm{HGD}$ & 1 & PD & 1 & $A(72)$ \\
\hline Larynx & 1 & Laryngeal Cancer & 1 & Laryngectomy & 1 & $\mathrm{D}(27)$ \\
\hline
\end{tabular}

$D$ dead, $A$ alive, $C T$ chemotherapy, $E R$ endoscopic resection, $P D$ pancreaticoduodenectomy, $H G D$ high grade dysplasia 
Table 2 Site of incidental findings, results of investigation, reasons of non investigation of patients with pancreatic tumors who underwent PET/CT with diffuse uptake of the radiotracer

\begin{tabular}{|c|c|c|c|c|c|}
\hline \multirow[t]{2}{*}{ Site } & \multirow{2}{*}{$\begin{array}{l}\text { Total Number } \\
\text { of Patients }\end{array}$} & \multicolumn{2}{|c|}{ Investigated } & \multicolumn{2}{|c|}{ Reason of Non Investigation } \\
\hline & & $\overline{\mathrm{N}^{0}}$ & Pathology & $\overline{\mathrm{N}^{\circ}}$ & Reason \\
\hline Oesophagus & 1 & 1 & Oesophagitis & - & - \\
\hline Stomach & 1 & 1 & Gastritis & - & - \\
\hline \multirow[t]{2}{*}{ Colon } & 20 & 5 & 1 Hyperplastic Polyps & 8 & Physiological uptake \\
\hline & & & & 7 & Advanced Disease \\
\hline Rectum & 2 & 1 & Proctitis & - & - \\
\hline Thyroid & 2 & 2 & Benign Goiter & - & - \\
\hline
\end{tabular}

$(n=1)$, stomach $(n=1)$ (Table 2$)$. The colon was the most common site of FDG uptake in all groups (Figs. 1, 2). All patients with focal uptake were investigated with colonoscopy $(n=23)$, contrast-enhanced CT $(n=5)$, gastroscopy $(n=1)$, mammography $(n=1)$, laryngoscopy $(n=1)$. Investigations were performed in 10 patients with diffuse uptake
(5 colonoscopy, 2 gastroscopy, 2 ultrasonography and fineneedle aspiration, 1 sigmoidoscopy).

Of the 31 patients investigated for focal FDG uptake (19 patients with primary malignant tumors and 12 benign pancreatic neoplasms), invasive malignancy was diagnosed in 22 patients: 14 colon adenocarcinoma, 4

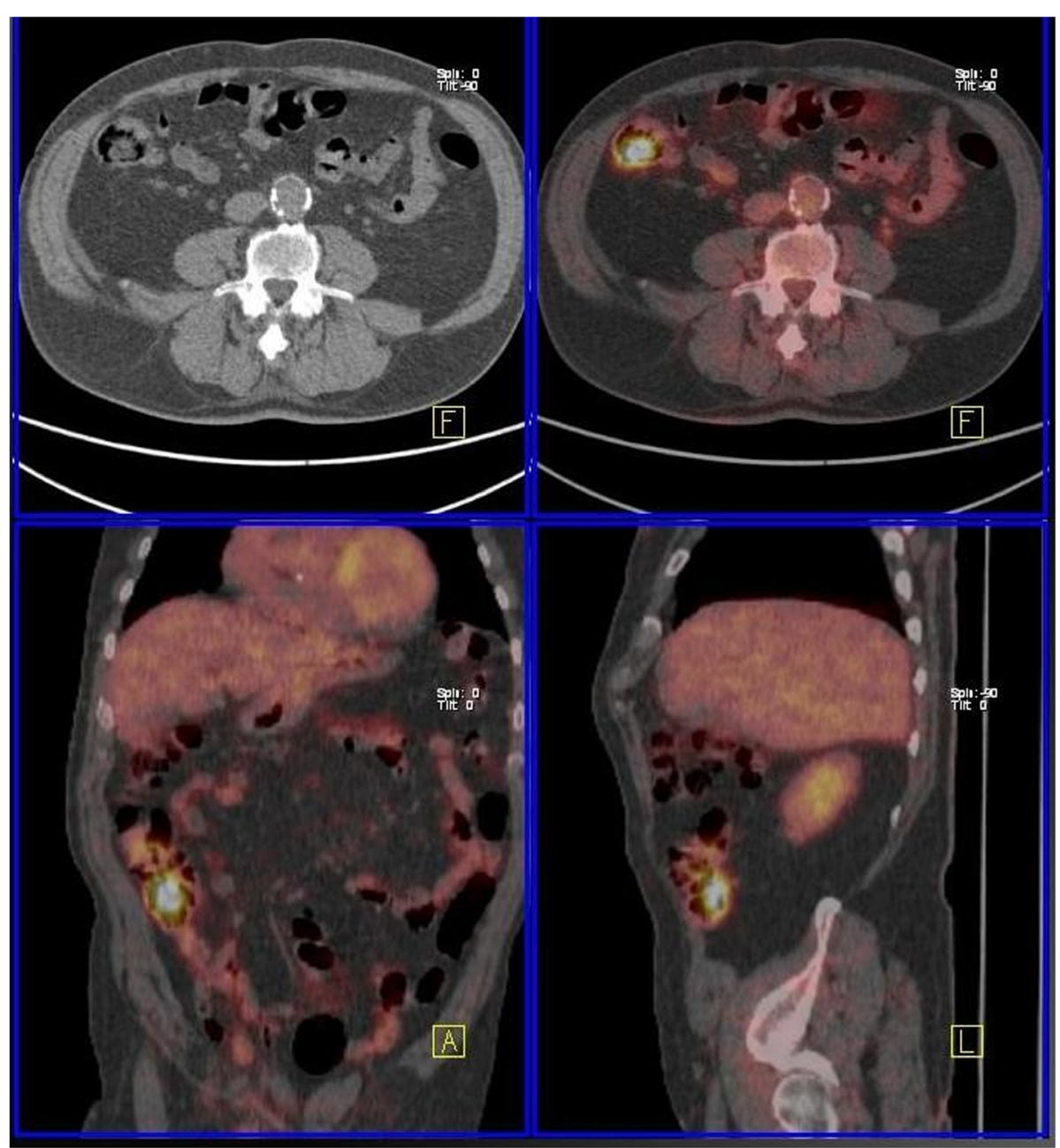

Fig. 1 PET/CT incidental detection of cancer of the ascending colon associated with branch-type IPMN of the pancreatic head (PET negative) 


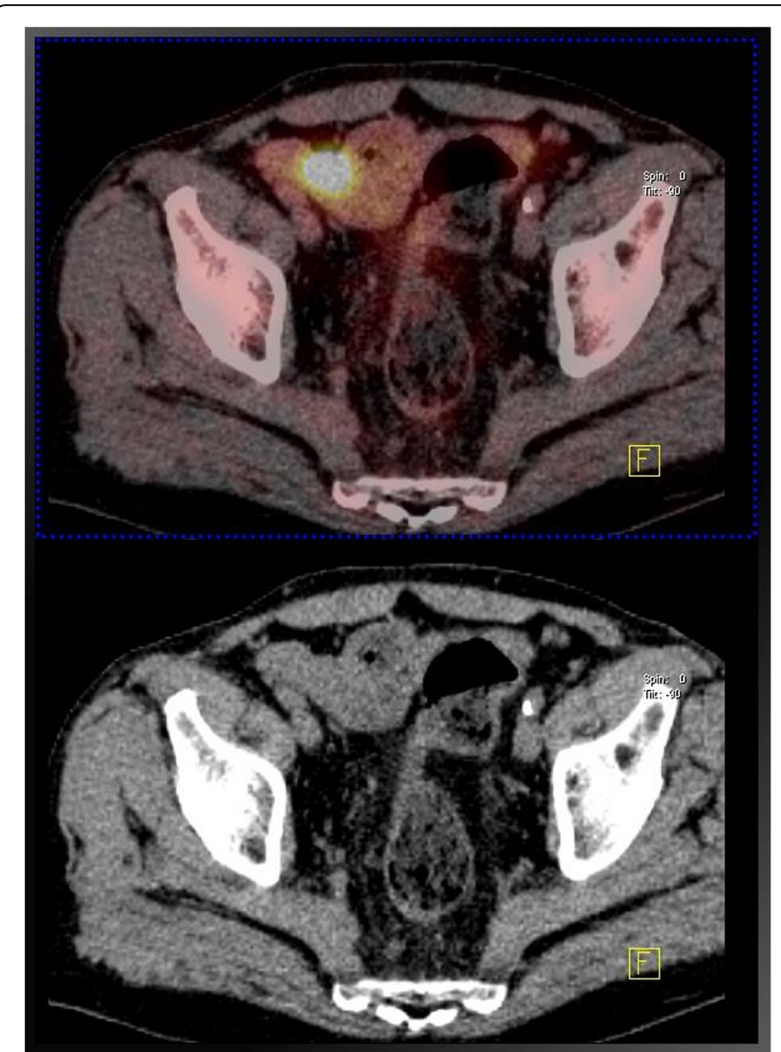

Fig. 2 PET/CT incidental detection of cancer of the sigmoid colon 39 months after pancreatico-duodenectomy for pancreatic cancer

lung adenocarcinoma (Fig. 3), 1 cancer of the larynx, 1 urothelial cancer (Fig. 4), 1 breast cancer, and 1 colon metastasis from pancreatic cancer. Among the remaining 9 patients, 7 showed colonic $(n=6)$ or duodenal $(n=1)$ polyps with high-grade dysplasia, and two patients did not show any pathology. Fourteen patients underwent colectomy, 6 endoscopic removal of colonic polyps, 3 lung lobectomy, 1 laryngectomy, 1 pancreaticoduodenectomy, and 1 nephrectomy. Five patients did not undergo surgery: three for advanced disease (1 lung cancer, 1 breast cancer, and 1 pancreatic cancer metastasis), and two for not evidence of disease (false positive). Among patients with pathological uptake of FDG during initial work-up for pancreatic cancer ( $n=7$ patients), in 5 patients detection of second tumor changed the operative management and a colectomy was associated with the pancreatic resection. The other two patients did not undergo pancreatic resection for advanced cancer. After a median follow-up of 29 months (range 14-96 months), 2 patients investigated for pancreatic cancer are alive and free of disease, 4 and 5 years after resection of lung cancer and colon cancer, respectively. The remaining patients died of progression of disease, with a median overall survival of 20 months (range 5-96 months), with 5 long survivors (survival $>60$ months) .
Among the 12 patients investigated for benign pancreatic disease (9 IPMNs and 3 cystadenomas), 8 patients are alive and disease-free (median survival time 48 months) while 2 patients died for colon cancer $(n=1)$ and urothelial cancer $(n=1) 37$ and 16 months after surgery, respectively. The remaining 2 patients died for causes unrelated to cancer.

Of the 10 patients investigated for diffuse uptake, hyperplastic colonic polyps were detected in 1 patient, proctitis in 1, gastritis in 1, oesophagitis in 1, thyroid goiter in 2, no abnormality in the remaining 4 patients (Table 2). None of these patients developed a second cancer during the entire follow-up. Quantitative analysis did not show significant difference between lesions with focal uptake (mean SUV $=6.4$, range 3.0-12.5) and diffuse uptake (mean SUV 5.1, range 2.5-10.0).

A total of 51 patients underwent PET/CT during the follow-up after resection of pancreatic cancer. Eleven patients showed extrapancreatic focal uptake of FDG and 9 had resection of confirmed second cancer; one patient is alive 61 months after operation, while 8 patients died for recurrent pancreatic or colon cancer with a median survival time of 41 months (range 13-118 months). The remaining two patients did not have evidence of disease (colon) and are still alive and well after 1 and 3 years, respectively (Table 3 ).

\section{Discussion}

FDG-PET offers the unique opportunity to provide not only whole-body images, but also metabolic or functional informations regarding the tumor tissue. Moreover, the widespread availability of this imaging technique led to increasing number of incidental findings: this necessarily suggest further investigations in order to exclude malignancies. As previously reported by other studies dealing with PET/CT in different malignancies, we have observed an increasing number of extrapancreatic FDG uptake in patients with pancreatic neoplasms. So, we evaluated our experience of incidental findings of PET/CT performed for patients with neoplasms of the pancreas: to our knowledge this is the first study dedicated to this specific topic. An incidental finding was detected in $14 \%$ of the patients in our study, and it was further investigated in $72 \%$ of cases (all with focal and 10 out of 25 patients with diffuse uptake). Second malignant or premalignant lesions were confirmed in all but one patient who showed PET/CT with focal uptake: the remaining patient with a focal FDG uptake had a colonic metastasis from pancreatic cancer confirmed by pathologic examination. The number of incidental findings in our study appears higher than that reported by other authors $[10,11]$ but much greater incidence (more than 20\%) has been reported for other types of primary neoplasms $[9,12]$.

Most of our PET/CT incidental findings were localized in the large bowel, in according with previous studies 


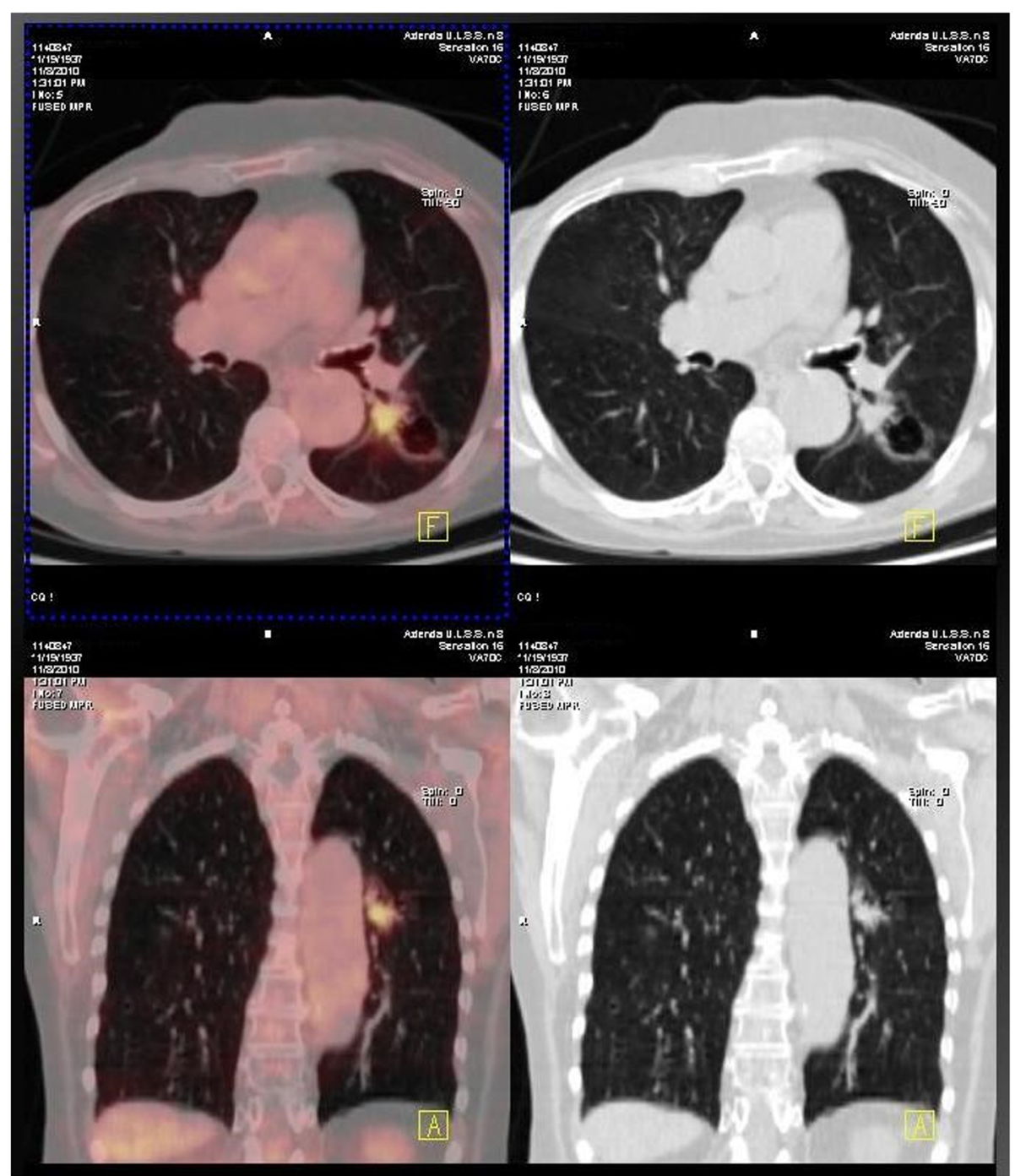

Fig. 3 PET/CT incidental detection of left pulmonary adenocarcinoma 31 months after distal pancreatectomy for pancreatic cancer

including patients with different primary tumors [13-15]. In our study a malignant or premalignant lesion was detected in $74 \%$ of patients who underwent endoscopy. A confirmed pathologic lesion was obtained in all but two patients with focal FDG uptake, while none of the patients investigated for diffuse FDG uptake showed unexpected tumors. This finding outlines the concept that when a focal uptake of FDG is detected, a high suspicion of malignancy is suggested, and further investigations are necessary [16-18]. One could argue that detection of a second tumor in patients with such an aggressive disease as pancreatic cancer does not modify the poor prognosis, and it is without a clinical significance. However, in our experience, some patients who underwent resection of a second neoplasm incidentally detected by PET/CT, showed prolonged survival: this is particularly true for lesions incidentally detected in the follow-up of patients without recurrence after resection of pancreatic cancer. So, as we previously reported [19], PET/CT is useful not only for the staging of pancreatic malignancy, but also for the postoperative surveillance of resected pancreatic cancer. Moreover, it has been reported that IPMNs are at risk of association with extra-pancreatic malignancies [20, 21], but contrasting results are also suggested [22, 23]. In our study, 21 patients with benign IPMNs showed extra-pancreatic PET/CT incidental findings: in 11 patients a focal uptake of the radiotracer was evident, and a second malignancy was resected in 9 .

In our Center, after an initial period when PET/CT was performed (whenever possible) in almost all patients with pancreatic cancer, we now perform it to stage resectable cancer and, when indicated, during the follow- 


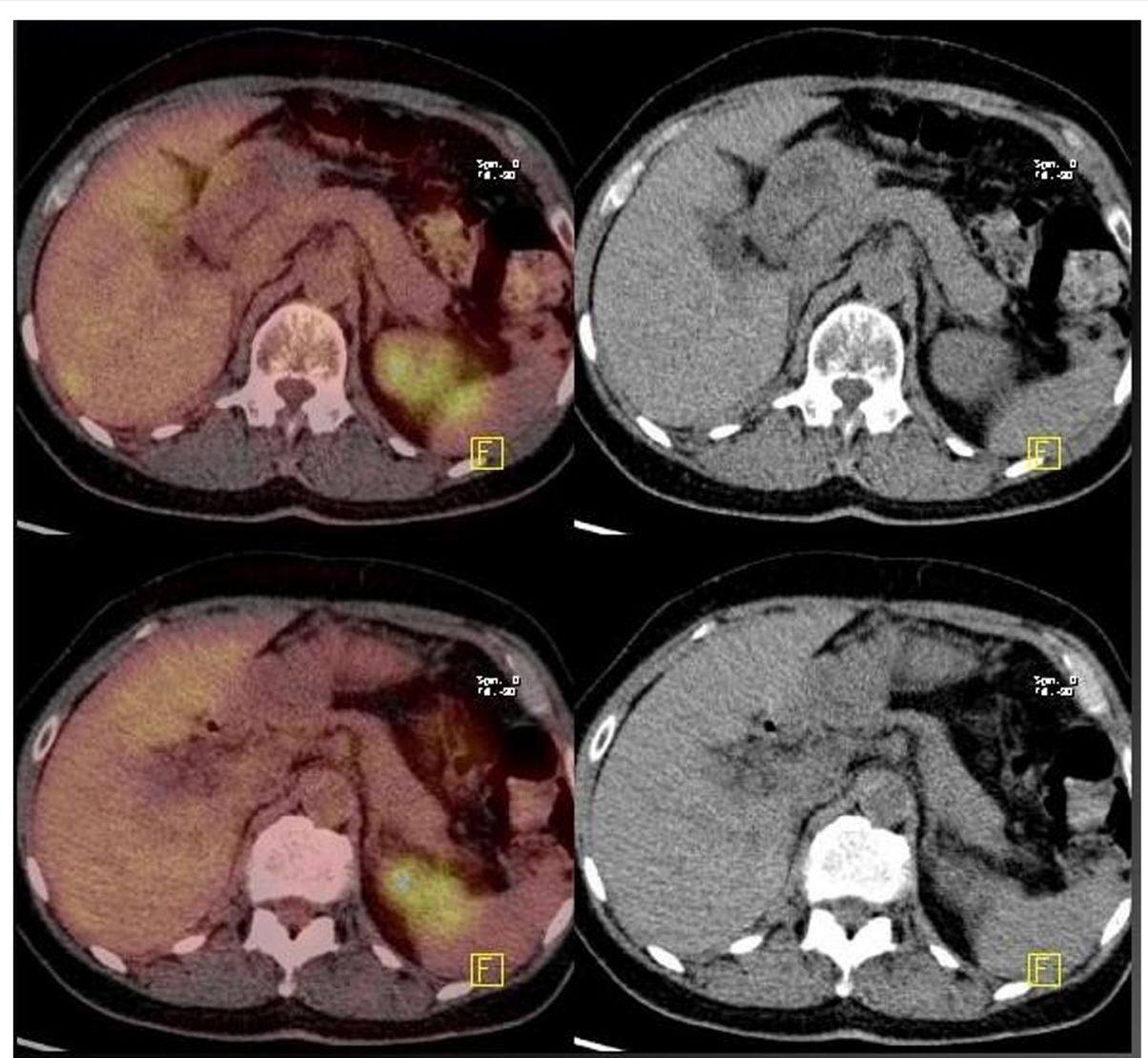

Fig. 4 PET/CT incidental detection of left ureteral cancer associated with IPMN (adenoma) of the pancreatic tail (PET negative)

up of resected patients. Moreover, we think that PET/CT can be an useful tool also during follow-up of selected patients with IPMNs. On the contrary, we have observed that PET/CT is unlikely to modify the management of patients with metastatic pancreatic cancer.

\section{Conclusions}

As in other tumors, our study reveals that unexpected FDG uptake is frequent in patients having PET/CT

Table 3 Site of incidental findings, results of investigation of patients who underwent PET/CT with focal uptake of the radiotracer during the follow-up after resection of pancreatic tumors

\begin{tabular}{llll}
\hline Site & $\begin{array}{l}\text { Total Number } \\
\text { of Patients }\end{array}$ & \multicolumn{2}{l}{ Investigated } \\
\cline { 3 - 4 } \cline { 3 - 4 } & 2 & 2 & Pathology \\
\hline Lung & 1 & 1 & Cancer \\
Larynx & 7 & 7 & Cancer \\
Colon & 1 & 1 & Cancer $+2 \mathrm{FP}^{\mathrm{a}}$ \\
Rectum & & & HGD polyp \\
\hline
\end{tabular}

FP false positive, $H G D$ high grade dysplasia

${ }^{a}$ two patients with colonic focal uptake were investigated with colonoscopy and CT scan, which resulted negative for pathology in both cases investigation for pancreatic neoplasms. Focal uptake is likely to be a malignancy and deserves accurate examination, although the stage and the poor prognosis of primary cancer should be kept in mind. Some selected patients (with benign IPMN, or in follow-up after resection of pancreatic cancer) may benefit from the aggressive treatment of incidental lesions and show survival benefit.

\section{Abbreviations}

18F-FDG: 18F-Fluorodeoxyglucose; A: Alive; CT: Chemotherapy; D: Dead; ER: Endoscopic resection; FP: False positive; HGD: High grade dysplasia; IPMN: Intraductal papillary mucinous neoplasms;

PD: Pancreaticoduodenectomy; PET/CT: Positron emission tomography/ computed tomography; SUV: Standardized uptake value

Availability of data and materials

All the data are available without restriction. Researches can obtain data by contacting the corresponding author.

\section{Authors' contributions}

LM and CS conceived the study and drafted the manuscript; LM, AF, MV and NP collected and analyzed the data; SB made PET/CT interpretation. All authors read and approved the final manuscript. Reviewer (DISCOG, Department of Surgery, Oncology and Gastroenterology, 
University of Padua, Italy). All study participants provided informed written consent prior to study enrollment.

\section{Consent for publication}

All study participants provided informed written consent prior to study enrollment.

\section{Competing interests}

The Authors declare that they have no competing interests.

\section{Publisher's Note}

Springer Nature remains neutral with regard to jurisdictional claims in published maps and institutional affiliations.

\section{Author details}

'Department of Surgery, Oncology and Gastroenterology, 3rd Surgical Clinic, University of Padua, Padua, Italy. ${ }^{2}$ Department of Nuclear Medicine, Castelfranco Veneto General Hospital, Castelfranco Veneto, Treviso, Italy.

${ }^{3}$ Gastroenterology Unit, University of Padua, Padua, Italy.

Received: 24 January 2018 Accepted: 30 April 2018

Published online: 04 May 2018

\section{References}

1. Hustinx R, Benard F, Alavi A. Whole-body FDG-PET imaging in the management of patients with cancer. Semin Nucl Med. 2002;32:35-46.

2. Pham KH, Ramawamy MR, Hawkins RA. Advances in positron emission tomography imaging in the GI tract. Gastrointest Endosc. 2002;55(Suppl 7) 553-63.

3. Van Hertum Rl, Fawvaz RA. The role of nuclear medicine in the evaluation of pancreatic disease. Surg Clin North Am. 2001;8:345-58.

4. Sone Y, Sobajima A, Kawachi T, Kohara S, Kato K, Naganawa S. Ability of 18fluorodeoxyglucose positron emission tomography/CT to detect incidental cancer. Bt. J Radiol. 2014:87:20140030.

5. Minamimoto $R$, Senda M, Jinnouchi $S$, Terauchi $T$, Yoshida T, Murano T, Fukuda $H$, linuma $T$, Uno K, Nishizawa S, Tsukamoto E, Iwata H, Inoue T, Oguchi K, Nakashima R, Inoue T. The current status of an FDG-PET cancer screening program in Japan, based on a 4-year (2006-2009), nationwide survey. Ann Nucl Med. 2013;27:46-57.

6. Haerle SK, Strobel K, Hany TF, Sidler D, Stoeckli SJ. 18-FDG-PET/CT versus panendoscopy for the detection of synchronous second primary tumors in patients with head and neck squamous cell carcinoma. Head Neck. 2010;32: 319-25.

7. Adams HL, Janunoo SS. Clinical significance of incidental findings on staging positron emission tomography for oesophago-gastric malignancies. Ann R Coll Surg Engl. 2014;96:207-10.

8. Sato K, Ozaki K, Fujiwara S, Oh I, Matsuyama T, Ohmine K, Suzuki T, Mori M, Nagai T, Muroi K, Ozawa K. Incidental carcinomas detected by PET/CT scans in patients with malignant lymphoma. Int J Hematol. 2010;92:647-50.

9. Chopra A, Ford A, de Noronha R, Matthews S. Incidental findings on positron emission tomography/CT scans performed in the investigation of lung cancer. Br J Radiol. 2012;85:e229-37.

10. Ishimori T, Patel PV, Wahl RL. Detection of unexpected additional primary malignancies with PET/CT. J Nucl Med. 2005:46:752.757.

11. Israel O, Yefremov N, Bar-Shalom R, Kagana O, Frenkel A, Zet K, Fischer D. PET/CT detection of unexpected gastrointestinal foci of 18-FDG uptake: incidence, localization patterns and clinical significance. J Nucl Med. 2005; 46:758-62.

12. Vella-Bocaud J, Papathanassiou D, Bouche O, Prevost A, Lestra T, Dury S, Vallerand $\mathrm{H}$, Perotin JM, Launois C, Boissiere L, Brasseur M, Lebargy F, Deslee G. Incidental gastrointestinal 18F-Fluorodeoxyglucose uptake associated with lung cancer. BMC Pulm Med. 2015;15:152.

13. Andia GS, Soriano AP, Ortega Candil A, Cabrera Martin MN, Gonzalez Roiz JJ, Ortiz Zapata JJ, Cardona Arbonies J, Lapena Gutierrez L, Carreras Delgado $J$. Clinical relevance of incidental finding of focal uptakes in the colon during 18-FDG PET/CT studies in oncologic patients without known colorectal carcinoma and evaluation of the impact on management. Rev Esp Med Nucl. 2012;31:15-21.

14. Goldin E, Mahamid M, Koslowsky B, Shteingart S, Dubner Y, Lalazar G, Wengrover D. Unexpected FDG-PET uptake in the gastrointestinal tract: endoscopic and histopathological correlations. World J Gastroenterol. 2014; 20:4377-81.

15. Peng J, He Y, Xu J, Sheng J, Cai S, Zhang Z. Detection of incidental colorectal tumours with 18F-labelled 2-fluoro-2-deoxyglucose positron emission tomography/computed tomography scans: results of a prospective study. Color Dis. 2011;13:e374-8.

16. Tatidi $\mathrm{R}$, Jadvar H, Bading JR, Conti PS. Incidental colonic fluorodeoxyglucose uptake : correlation with colonoscopic and histopathologic findings. Radiology. 2002;224:783-7.

17. Treglia G, Calcagni ML, Rufini V, Leccisotti L, Meduri GM, Spitilli MG, Dambra DP, De Gaetano AM, Giordano A. Clinical significance of incidental focal colorectal 18F-fuorodeoxyglucose uptake: our experience and a review of the literature. Color Dis. 2011:14:174-80.

18. Kunawudhi A, Wong AK, Alkasab TK, Mahmood U. Accuracy of FDG-PET/CT for detection of incidental premalignant and malignant colonic lesionscorrelations with colonoscopic and histopathologic findings. Asian Pac J Cancer Prev. 2016:17:4143-7.

19. Sperti C, Pasquali C, Bissoli S, Chierichetti F, Liessi G, Pedrazzoli S. Tumor relapse after pancreatic cancer resection is detected earlier by 18-FDG PET than by CT. J Gastrointest Surg. 2010;14:131-40.

20. Reid-Lombardo KM, Mathis KL, Wood CM, Harmsen WS, Sarr MG. Frequency of extrapancreatic neoplasms in intraductal papillary mucinous neoplasms of the pancreas: implications for management. Ann Surg. 2010;251:64-9.

21. Larghi A, Panic N, Capurso G, Leoncini E, Arzani D, Salvia R, Del Chiaro M, Frulloni L, Arcidiacono PG, Zerbi A, Manta R, Fabbri C, Ventrucci M, Tarantino I, Piciucchi M, Carnuccio A, Boggi U, Costamagna G, Delle Fave G, Pezzili R, Bassi C, Bulajic M, Ricciardi W, Boccia S. Prevalence and risk factors of extrapancreatic malignancies in a large cohort of patients with intraductal papillary mucinous neoplasm (IPMN) of the pancreas. Ann Oncol. 2013;24:1907-11.

22. Kawakubo K, Tada M, Isayama H, Sasahira N, Nakai Y, Yamamoto K, Kogure H, Sasaki T, Hirano K, ljichi H, Tateishi K, Yoshida H, Koike K. Incidence of extrapancreatic malignancies in patients with intraductal papillary mucinous neoplasms of the pancreas. Gut. 2011;60:1249-53.

23. Malleo G, Marchegiani G, Borin A, Capelli P, Accordini F, Butturini G, Pederzoli P, Bassi C, Salvia R. Observational study of the incidence of pancreatic and extraèpancreatic malignancies during surveillance of patients with branch-duct intraductal papillary mucinous neoplasm. Ann Surg. 2015:281:984-90.

\section{Ready to submit your research? Choose BMC and benefit from:}

- fast, convenient online submission

- thorough peer review by experienced researchers in your field

- rapid publication on acceptance

- support for research data, including large and complex data types

- gold Open Access which fosters wider collaboration and increased citations

- maximum visibility for your research: over $100 \mathrm{M}$ website views per year

At BMC, research is always in progress.

Learn more biomedcentral.com/submissions 